\title{
Biomass estimation of cultivated red algae Pyropia using unmanned aerial platform based multispectral imaging
}

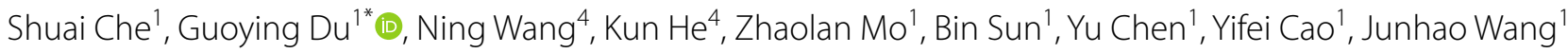
and Yunxiang $\mathrm{MaO}^{2,3^{*}}$

\begin{abstract}
Background: Pyropia is an economically advantageous genus of red macroalgae, which has been cultivated in the coastal areas of East Asia for over 300 years. Realizing estimation of macroalgae biomass in a high-throughput way would great benefit their cultivation management and research on breeding and phenomics. However, the conventional method is labour-intensive, time-consuming, manually destructive, and prone to human error. Nowadays, highthroughput phenotyping using unmanned aerial vehicle (UAV)-based spectral imaging is widely used for terrestrial crops, grassland, and forest, but no such application in marine aquaculture has been reported.
\end{abstract}

Results: In this study, multispectral images of cultivated Pyropia yezoensis were taken using a UAV system in the north of Haizhou Bay in the midwestern coast of Yellow Sea. The exposure period of P. yezoensis was utilized to prevent the significant shielding effect of seawater on the reflectance spectrum. The vegetation indices of normalized difference vegetation index (NDVI), ratio vegetation index (RVI), difference vegetation index (DVI) and normalized difference of red edge (NDRE) were derived and indicated no significant difference between the time that P.yezoensis was completely exposed to the air and $1 \mathrm{~h}$ later. The regression models of the vegetation indices and P.yezoensis biomass per unit area were established and validated. The quadratic model of DVI (Biomass $=-5.550 \mathrm{DVI}+105.410 \mathrm{DVI}+7.530$ ) showed more accuracy than the other index or indices combination, with the highest coefficient of determination $\left(R^{2}\right)$, root mean square error (RMSE), and relative estimated accuracy (Ac) values of $0.925,8.06$, and $74.93 \%$, respectively. The regression model was further validated by consistently predicting the biomass with a high $R^{2}$ value of 0.918 , RMSE of 8.80 , and Ac of $82.25 \%$.

Conclusions: This study suggests that the biomass of Pyropia can be effectively estimated using UAV-based spectral imaging with high accuracy and consistency. It also implied that multispectral aerial imaging is potential to assist digital management and phenomics research on cultivated macroalgae in a high-throughput way.

Keywords: Pyropia, Biomass estimation, Unmanned aerial platform, Multispectral image, Algal phenomics

*Correspondence: dugu0923@ouc.edu.cn; yxmao@hntou.edu.cn ${ }^{1}$ Key Laboratory of Marine Genetics and Breeding (Ministry

of Education), College of Marine Life Sciences, Ocean University of China, Qingdao 266003, People's Republic of China

${ }^{2}$ Key Laboratory of Utilization and Conservation of Tropical Marine Bioresource (Ministry of Education), College of Fisheries and Life Science, Hainan Tropical Ocean University, Sanya 572022, People's Republic of China

Full list of author information is available at the end of the article

\section{Background}

Macroalgae contributes to around $10 \%$ of total global marine primary productivity, and its aquaculture production constitutes approximately $28 \%$ of total world marine aquaculture production by weight $[12,43]$. Macroalgae production is economically important for providing food, medicine, cosmetics, and biofuel $[13,14]$. The red macroalgae genus Pyropia (common name nori or laver), has

(c) The Author(s) 2021. This article is licensed under a Creative Commons Attribution 4.0 International License, which permits use, sharing, adaptation, distribution and reproduction in any medium or format, as long as you give appropriate credit to the original author(s) and the source, provide a link to the Creative Commons licence, and indicate if changes were made. The images or other third party material in this article are included in the article's Creative Commons licence, unless indicated otherwise in a credit line to the material. If material is not included in the article's Creative Commons licence and your intended use is not permitted by statutory regulation or exceeds the permitted use, you will need to obtain permission directly from the copyright holder. To view a copy of this licence, visit http://creativeco mmons.org/licenses/by/4.0/. The Creative Commons Public Domain Dedication waiver (http://creativecommons.org/publicdomain/ zero/1.0/) applies to the data made available in this article, unless otherwise stated in a credit line to the data. 
been cultivated and consumed in East and Southeast Asia for over 300 years $[3,14,30]$. Up to 2.56 million tonnes of Pyropia (fresh weight) were harvested in 2017 and valued at approximately US $\$ 2.32$ billion (FAO [12]. Fisheries and Aquaculture Information and Statistics Branch 2019). In comparison to other cultivated macroalgae, Pyropia has the highest commercial value per unit mass at $\$ 905$ per tonne. It has high nutritional value, in particularly high protein content at $~ 25-30 \%$ of the blade dry weight and a delicious flavour $[3,12]$.

High-throughput phenotyping has been increasingly used in recent years in research on phenomics and breeding, as well as for the digital management of precision agriculture $[1,17,49]$. Among various measurable agronomic traits, biomass is the most basic, not only for evaluating the growth trend and estimating yield, but also for assessing the ecosystem services of vegetation [32, 38]. However, the conventional estimation of biomass is labour-intensive, time-consuming, manually destructive with a tendency to produce human error, and cannot provide data on large scale $[8,26]$. Using unmanned aerial vehicle (UAV)-based multispectral or hyperspectral imaging techniques makes high-throughput phenotyping more efficient, accurate, and precise, as well as being non-destructive. It has been widely used in terrestrial agricultural research and management $[42,46,57]$. Using this technique, spatial and temporal crop biomass data can be obtained in time and can be used to analyse crop responses to dynamic environment conditions [28, 34]. Several studies have used this technique to estimate the biomass of crops such as maize $[19,56]$, wheat $[5,35]$, rice $[9,52]$, barley $[2,40]$, soybean $[54,60]$, and rapeseed $[16,34]$.

Comparatively, the marine cultured macroalgae have been less studied than terrestrial plants [37]. Until now, it has no such research been published on high-throughput phenotyping of cultivated macroalgae using UAV-based spectral imaging. Besides the social and economic factors, it might be due to the more complex environmental conditions of coastal area where mariculture is carried out, besides resuspended sediments, and coloured dissolved organic matter from terrestrial runoff, which not only limit the survey range but also interfere the imaging quality $[21,51]$. Seawater can strongly absorb light in the red-near infrared (NIR) wavelength and reflects blue and green light, which in turn interferes with the spectral signal and influences the accuracy of imaging [20, 45]. However, for macroalgae floating on the seawater surface, especially for harmful macroalgae bloom, several studies have proved that it is feasible to estimate the biomass of Ulva prolifera, Sargassum natans, and Trichodesmium spp. based on spectral images $[10,21,51]$. Moreover, the benthic macroalgae such as Codium tomentosum, Laminaria saccharina, Corallina officinalis could be qualitative mapped by hyperspectral remote sensing in the coastal areas [6-8]. Therefore, theoretically, it is feasible to use UAV-based multispectral platform to estimate the biomass of cultivated macroalgae.

In the coast of Yellow Sea, Pyropia is cultivated on nets by three kinds of rafts: semi-floating, fixed pillars, or turnover (or full floating) (Fig. 1). The Pyropia nets are periodically exposed to the air during the low tide period, sometimes aided by artificial lifting, to follow the natural condition of Pyropia in the intertidal zone. This periodic exposure can decrease the epiphytes and competitors, and increases the protein content of Pyropia thallus [4, 29, 30]. Simultaneously, these specific exposure period can provide a time frame for piloting the high-throughput phenotyping using UAV-based spectral imaging on cultivated Pyropia.

In this study, Pyropia yezoensis, one of two widely cultivated Pyropia species, was investigated using UAV-based spectral imaging. The aim was to establish an algorithm model of biomass based on multispectral imaging data,

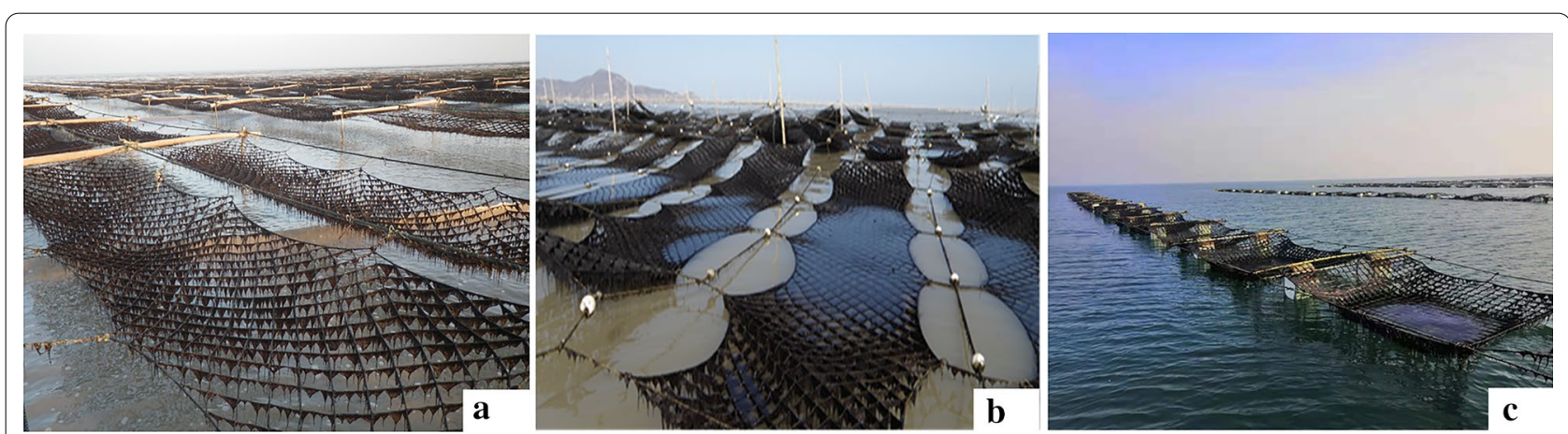

Fig. 1 Three different cultivation methods of Pyropia cultivation. a Semifloating nets on the intertidal zone; $\mathbf{b}$ Nets on fixed pillars in the shoal region; c Turnover nets in the deep water zone 
which could be used for estimating $P$. yezoensis biomass in an accurate, high-throughput, and non-destructive way.

\section{Results}

\section{Comparison of multispectral reflectance}

The multispectral reflectance of $P$. yezoensis submerged in seawater was very similar to that of seawater, but quite different to that of $P$. yezoensis exposed to the air, which implied that seawater had a significant effect on seaweed (Fig. 2a). Compared with exposed $P$. yezoensis, the submerged $P$. yezoensis (floating just below the surface of the seawater) showed that the reflectance spectrum significantly increased in the blue, green, and red wavelengths $(P<0.01$, Fig. $2 \mathrm{~b})$, and significantly decreased in the NIR wavelength $(P<0.01$, Fig. $2 \mathrm{~b})$. On the other hand, compared to seawater, for submerged $P$. yezoensis, its red edge reflectance which should be raised by $P$. yezoensis had no significant difference with that of seawater $(P>0.05$, Fig. 2b), neither did NIR reflectance $(P>0.05$, Fig. 2b). Therefore, the period of $P$. yezoensis exposure to the air was more optimal for multispectral aerial imaging and was used in the followed measurements.

\section{Assessment of dehydrated effect}

When exposed to the air, the water content of $P$. yezoensis thalli would gradually reduce and influence the reflection spectrum (Fig. 3). Laboratory experiments showed that the values of DVI, RVI, NDRE, and NDVI varied differently along with decreased relative water content (RWC) (Fig. 4). Compared with the control group (100\% RWC), there was no significant difference in $P$. yezoensis from $90 \%$ RWC to $10 \%$ RWC in the values of DVI. However, there were significant decrease for RVI and NDVI when the RWC was under $40 \%(P<0.01)$, and relatively for
NDRE under 50\% $(P<0.05)$. Generally, all four indices were relatively stable at RWC ranging from $100 \%$ to $60 \%$.

Further field experiments confirmed the suitable period for acquisition of aerial image data. The comparison between the time when P. yezoensis was completely exposed to the air and $1 \mathrm{~h}$ later showed that there was no significant change for the four vegetation indices (Fig. 5, $P>0.05)$, both on 6th and 7th January, 2019. This indicated that the spectral characters of $P$. yezoensis are stable during this period and suitable for data collection by aerial imaging.

\section{Biomass estimation models and accuracy assessment}

The strong and positive correlations existed between $P$. yezoensis biomass and individual vegetation index of DVI, RVI, NDVI, and NDRE, with correlation coefficients of $0.962,0.945,0.922$, and 0.849 , respectively (Table $1 ; \mathrm{n}=80, P<0.01$ ). This also confirmed that DVI, RVI, NDVI and NDRE were promising indicators for the biomass estimation. The calculation equations of biomass based on single or combined vegetation indices with their regression diagnostic plots of the predicted values and the distribution plots of residuals are shown in Figs. 6 and 7 . For the single vegetation index, the quadratic model performed better than that of the linear regressions with higher $\mathrm{R}^{2}$, Ac and lower RMSE (Fig. 6). The optimal regression equation was the quadratic model of DVI (Biomass $=-5.550 \mathrm{DVI}^{2}+105.410 \mathrm{DVI}+7.530$ ). Its $\mathrm{R}^{2}$, RMSE, and Ac were $0.925,8.06$, and $74.93 \%$, respectively, and residual interval was between -20.76 and 18.84 (Fig. 6). RVI and NDVI exhibited relatively high $R^{2}$ of above 0.8 , while NDRE showed relative lower $R^{2}$ values of 0.721 and 0.731 , respectively. For the combined vegetation indices, the regressions with vegetation indices of DVI and RVI had higher accuracy

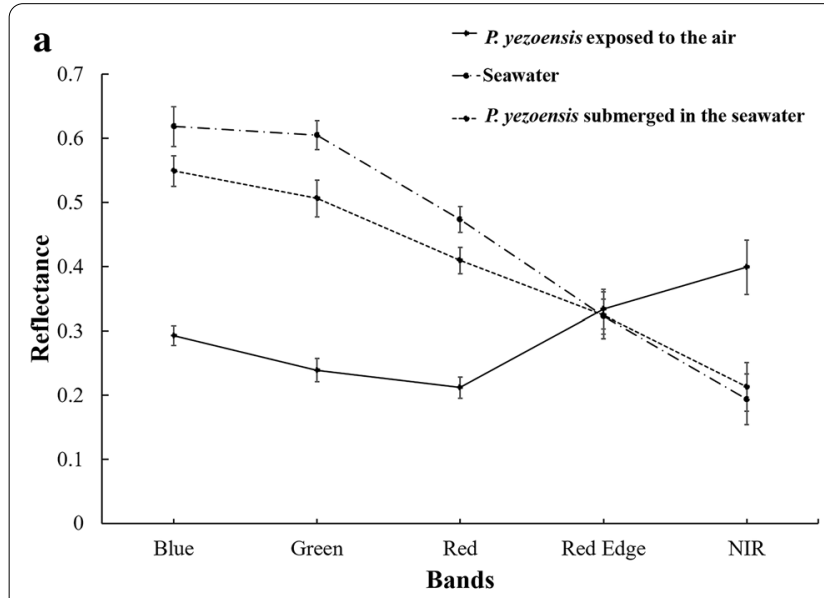

b

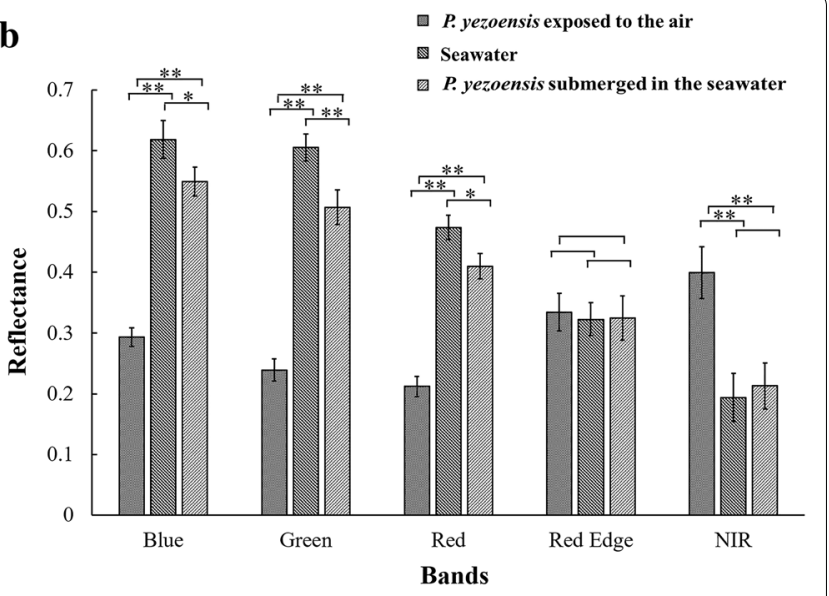

Fig. 2 Multispectral reflectance at five wave bands $\left({ }^{*} P<0.05 ;{ }^{* *} P<0.01\right)$ 


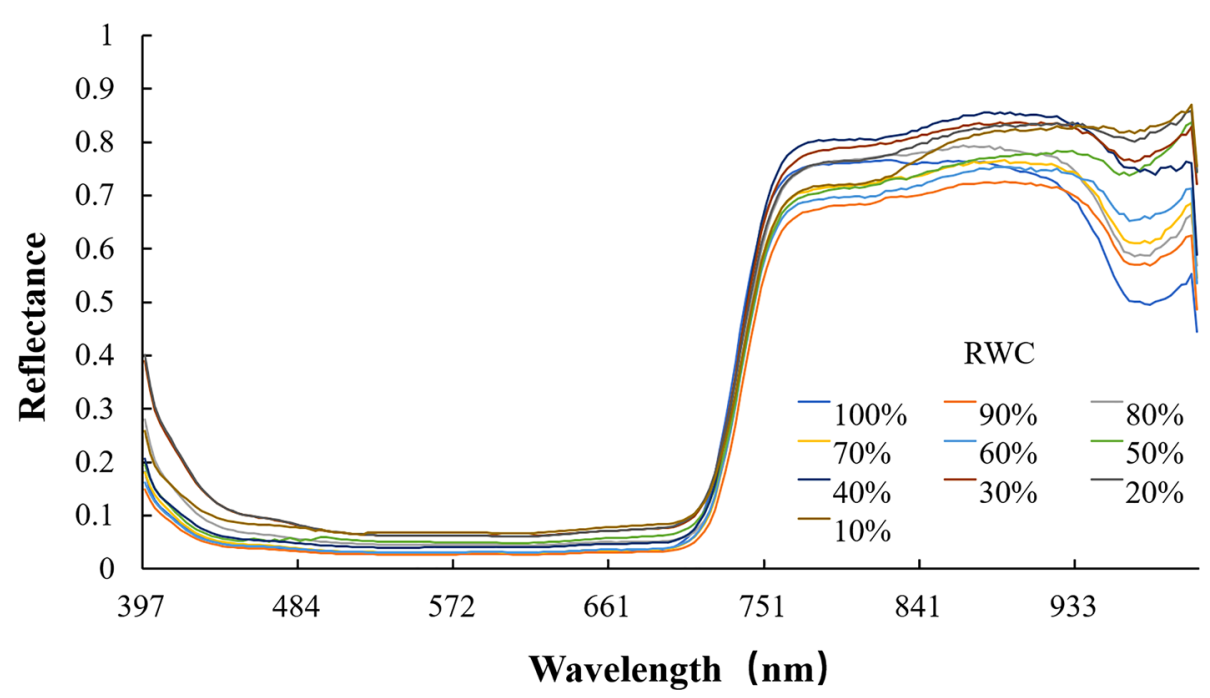

Fig. 3 Hyperspectral reflectance of P. yezoensis under different RWC

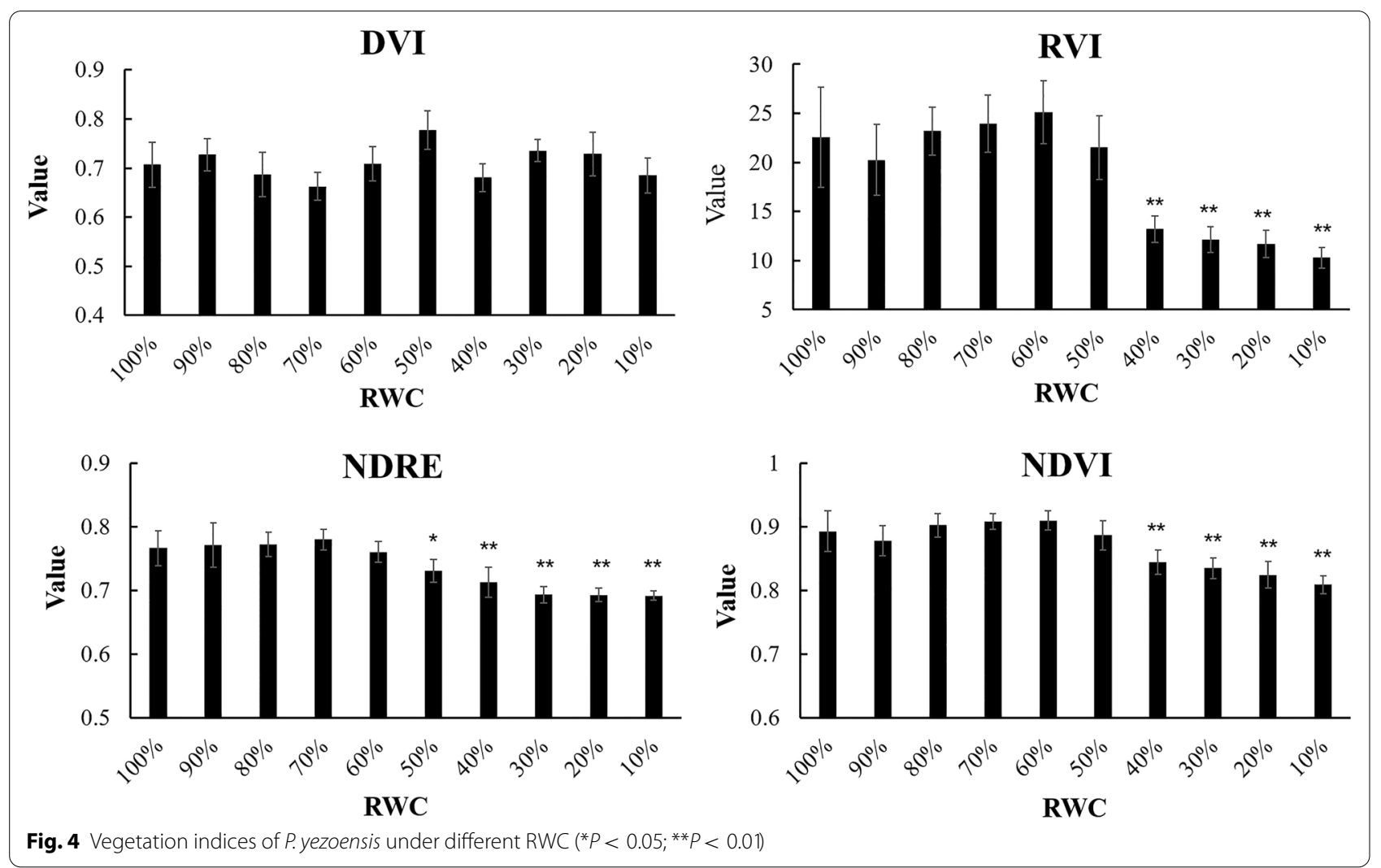

$\left(R^{2}>0.925\right.$, Ac $\left.>75 \%\right)$ than that with combination with NDVI and NDRE. However, the optimal combination was that of DVI, RVI, NDRE, and NDVI (Biomass $=84$. 122DVI + 3.763RVI + 7.341NDRE + 3.147NDVI + 4.421), which values of $\mathrm{R}^{2}$, RMSE, and Ac were 0.926, 8.01, an d $75.06 \%$, respectively, and the residual interval was between -21.78 and 21.02 (Fig. 7). Comparing the two optimal regression models based on single and combined indices respectively, although the later have little bit higher $\mathrm{R}^{2}$, Ac and lower RMSE, the residual interval 


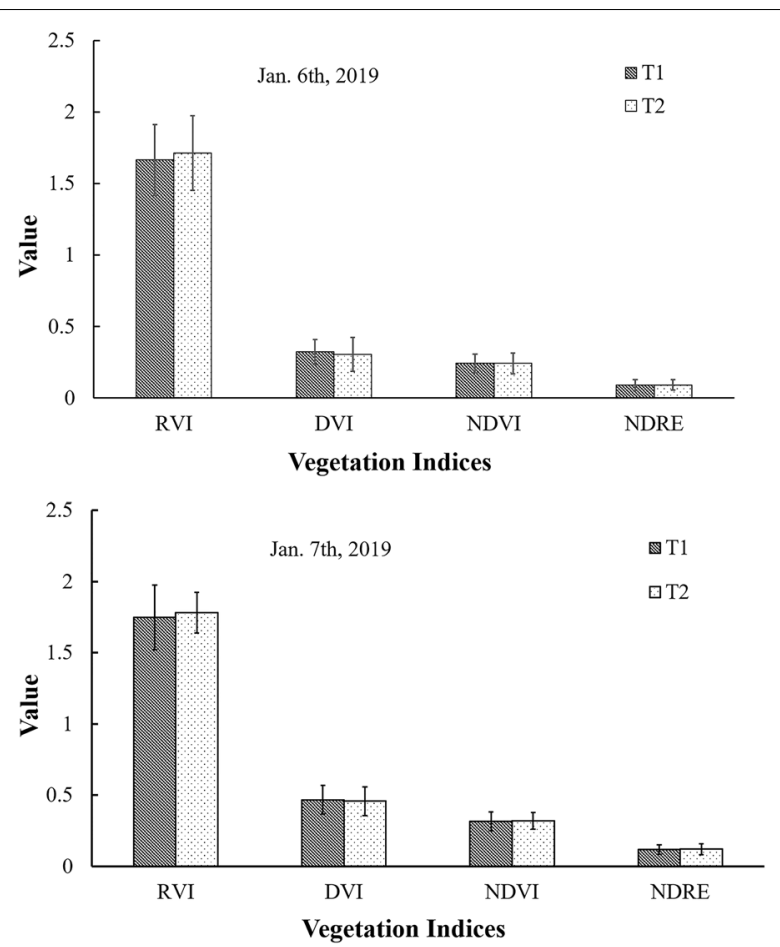

Fig. 5 Comparison of the vegetation indices between different exposure time. $T 1$, P.yezoensis once completely exposed to the air; $T 2$, $1 \mathrm{~h}$ after $\mathrm{T1}$

Table 1 Correlation coefficient of biomass with each vegetation index $(n=80, P<0.01)$

\begin{tabular}{lllll}
\hline & DVI & RVI & NDRE & NDVI \\
\hline Biomass & 0.962 & 0.945 & 0.849 & 0.922 \\
\hline
\end{tabular}

of the former (quadratic model of DVI) was smaller, which indicated a more accurate estimation of biomass. And save for simplification, the quadratic model of DVI $\left(\right.$ Biomass $\left.=-5.550 \mathrm{DVI}^{2}+105.410 \mathrm{DVI}+7.530\right)$ was considered more applicable for estimating the biomass of $P$. yezoensis.

\section{Model verification}

As it shown in Fig. 8, the validated values of biomass compared reliably with the estimated values based on the optimal regression model (Biomass $\left.=-5.550 \mathrm{DVI}^{2}+105.410 \mathrm{DVI}+7.530\right)$. The model consistently predicted the biomass with an $\mathrm{R}^{2}$ value of 0.918, RMSE of 8.80, and Ac of $82.25 \%$. The slope of the regression lines between the estimated and validated values was 0.943 , indicating a good prediction according to the criterion of Jamieson et al. [23].

\section{Discussion}

In this study, UAV-based multispectral imaging was introduced to estimate the biomass of Pyropia, and the results have demonstrated its potential application in marine aquaculture. Although techniques and facilities used in Pyropia cultivation have improved in recent years, the long distance offshore makes it difficult to supervise the situation on a large scale. The UAV-based spectral imaging system established in this study can be used for monitoring of the spatial and temporal status of cultivated Pyropia at large scales in a more high-throughput and cost-saving way.

In spectral acquisition, the variations of coastal environment would cause uncertainties. Previous studies reported that the environmental factors, such as clouds and tidal stage of the coastal area during UAV flight could result in the radiometric variability $[11,19]$. In this study, the multispectral images were collected under the similar sky conditions and the flight time was closed to solar noon [48]. In addition, the irradiance sensor loaded on the UAV platform could help rectify the difference of light conditions. Moreover, in coastal areas, seawater may influence the reflection values derived from the UAVbased spectral images. For instance, seawater can absorb in the red to NIR wavelengths and elevate the reflectance in the blue to green wavelengths $[10,21]$, especially in the coastal region with active river discharge and coastal turbid currents [31]. The Yellow Sea is specifically characterised by high turbidity, which would enhance the influence on spectral reflection [45]. Usually, the interference from different depths of seawater on spectral reflectance also limits the use of spectral imaging on most cultivated macroalgae, such as Saccharina japonica and Gracilariopsis lemaneiformis, which constantly submerged below the water surface throughout the culture period [24, 44, 53]. Compared to them, the cultivation of $P$. yezoensis involves periodic exposure out of the water which could be utilized for spectral imaging. In this study, it proved that the seawater significantly affected the reflection of $P$. yezoensis. Particularly, the seawater made it very difficult to distinguish between seawater and submerged $P$. yezoensis in the NIR wavelength, which is essential for calculating almost all vegetation indices. Therefore, at primary stage, multi-spectral imaging is suitable to be taken during the Pyropia exposure period. After solving the related techniques problems by developing higher resolution of the reflectance spectrum or eliminating disturbance from seawater, it could be feasible to use UAVbased spectral imaging for other cultivated macroalgae.

The vegetation index derived from spectral images has been widely used in the estimation of terrestrial crop biomass [35]. Same as terrestrial crops, the main pigment of the photosynthetic reaction centre of Pyropia is 

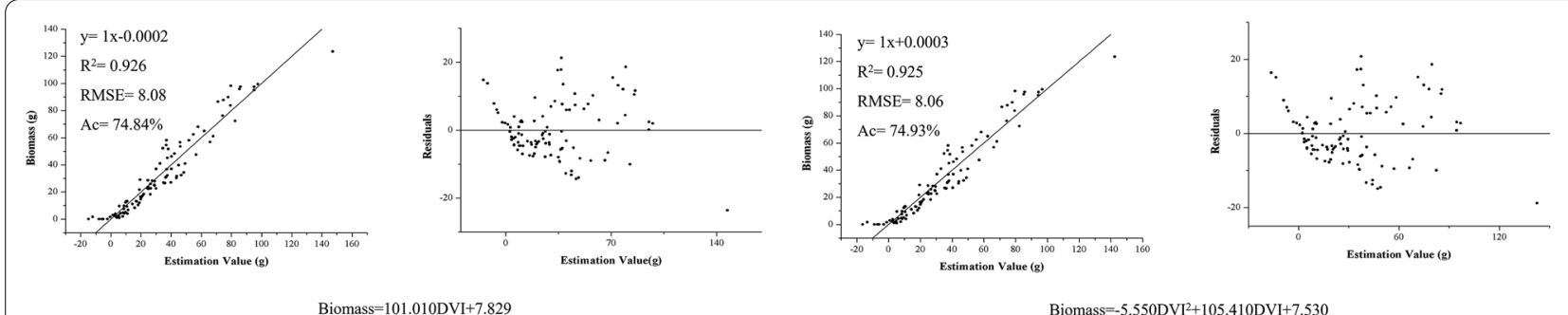

Biomass=101.010DVI+7.829

Biomass $=-5.550 \mathrm{DVI}^{2}+105.410 \mathrm{DVI}+7.530$
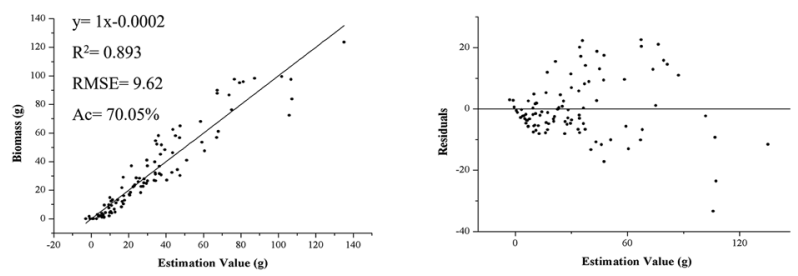

Biomass=32.098RVI-23.313
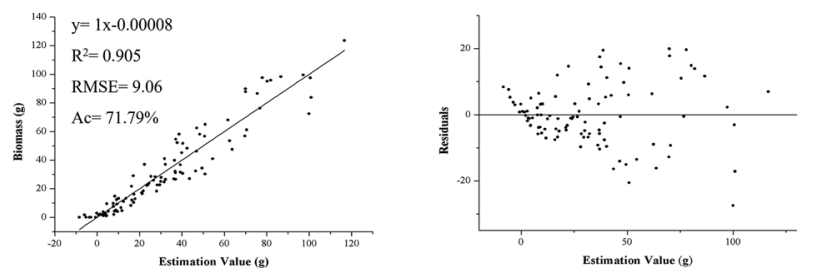

Biomass $=-3.179 \mathrm{RVI}^{2}+46.772 \mathrm{RVI}-36.78$
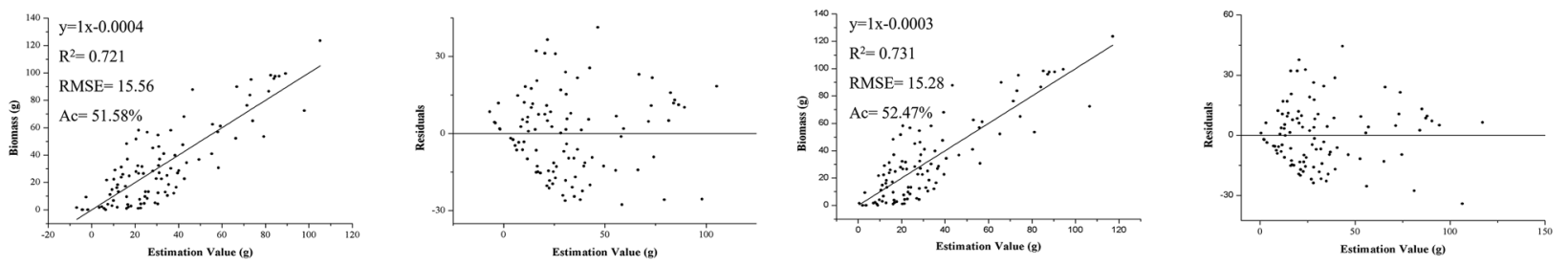

Biomass $=172.630 \mathrm{NDRE}+24.375$

Biomass $=120.470 \mathrm{NDRE}^{2}+145.100 \mathrm{NDRE}+22.836$
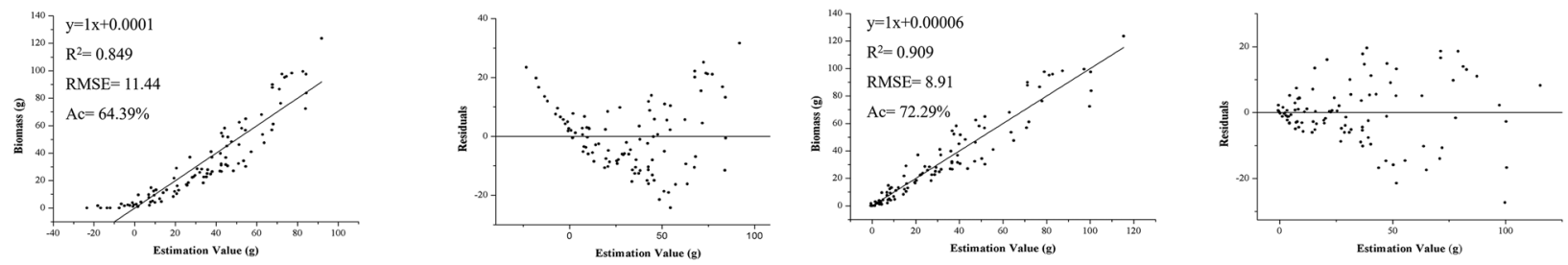

Biomass $=130.190 \mathrm{NDVI}+5.580$

Biomass $=151.470 \mathrm{NDVI}^{2}+64.260 \mathrm{NDVI}+6.131$

Fig. 6 Regression models and residuals-analysis plots based on single vegetation index $(n=80)$

chlorophyll-a [59], which primarily absorbs the light of the red and blue wavelengths but scatters most of solar radiation in the NIR wavelengths [45]. To obtain plant traits including biomass using spectral techniques, the reflectance of red and NIR wavelengths have been commonly used to calculate vegetation indices such as DVI, NDVI, and RVI [9, 16, 20, 28].

However, it showed that the spectral reflectance can be influenced by plant water stress $[18,36,39,58]$. Most Pyropia species lose $85-95 \%$ of cellular water during daytime low tide [4]. This dehydration would also affect the spectral characters of $P$. yezoensis and hence influence the biomass estimation. In this study, through laboratory and field experiments, we defined a stable time frame for collecting the UAV-based spectral imaging, which was within $1 \mathrm{~h}$ after $P$. yezoensis exposed to the air. The results showed that no effects on the values of DVI, RVI, NDVI, or NDRE. This time frame ensured the application of UAV-based spectral imaging for Pyropia biomass estimation using the four indices.

In this study, using UAV based five spectral band sensors, 4 existing vegetation indices were derived instead of creating a new index from specific spectral wavelengths. It was corroborated its convenience, effectiveness and relatively lower-costing by previous study [16]. Among the four indices, the DVI were finally 

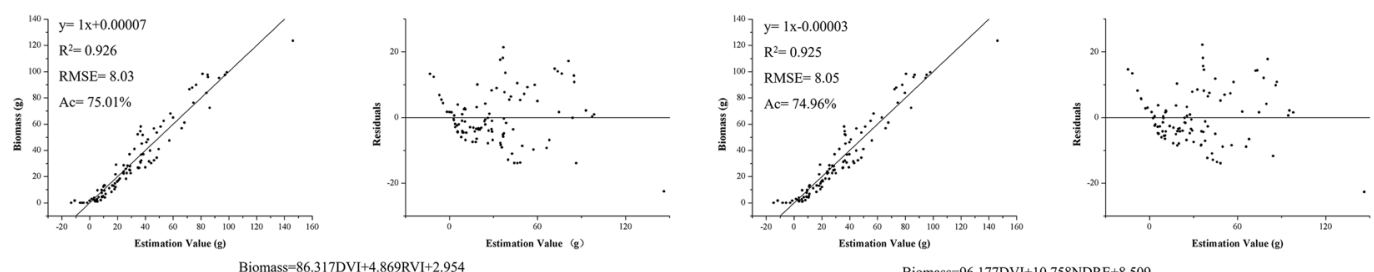

Biomass $=86.317 \mathrm{DVI}+4.869 \mathrm{RVI}+2.954$

Biomass $=96.177 \mathrm{DVI}+10.758 \mathrm{NDRE}+8.509$
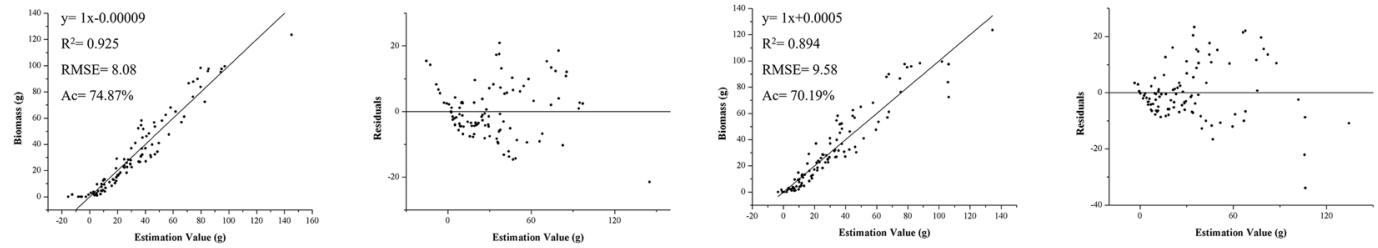

Biomass $=96.635 \mathrm{DVI}+6.16 \mathrm{NDVl}+7.624$

Biomass $=30.145 \mathrm{RVI}+13.23 \mathrm{NDRE}-20.535$
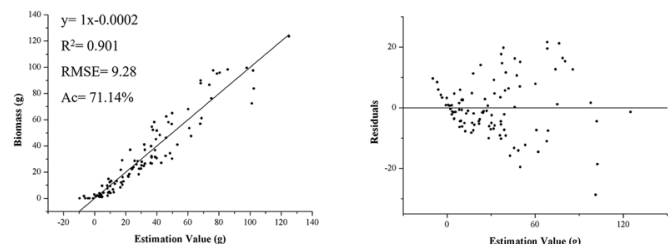

Biomass $=23.571 \mathrm{RVI}+37.542 \mathrm{NDVI}-16.241$
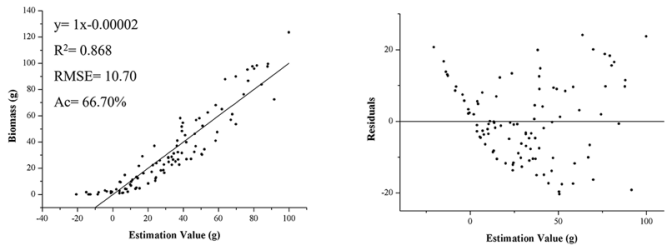

Biomass $=100.024 \mathrm{NDVI}+51.608 \mathrm{NDRE}+9.412$
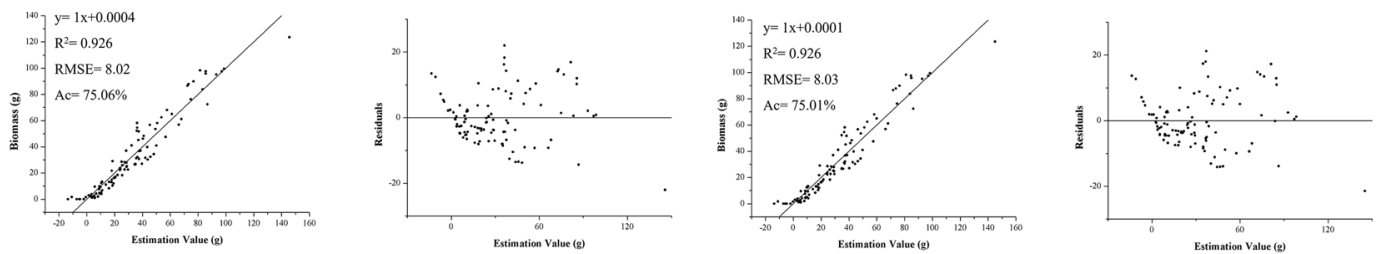

Biomass=85.7DVI+3.977RVI+7.361NDRE+4.312

Biomess=84.708DVI+4.648RVI+3 205NDVI+3.068
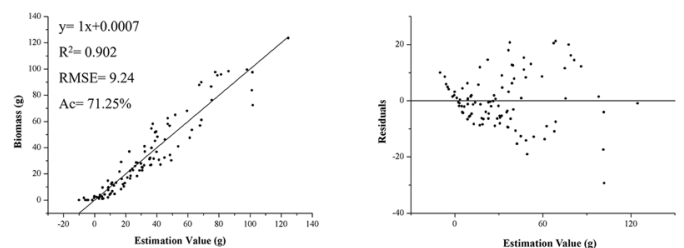

Biomass-21.948PVI+11. 721NDPE+37.07NDVI-13869
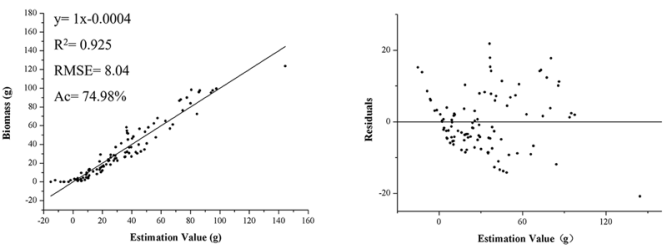

Biomass-92.579DVI+10.417NDRE $+5.286 \mathrm{NDVI}+8.312$
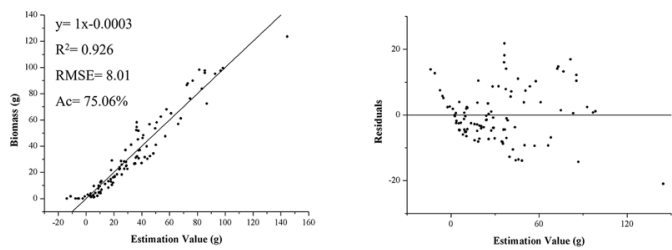

Biomass $=84.122 \mathrm{DVI}+3.763 \mathrm{RVI}+7.34 \mathrm{INDRE}+3.147 \mathrm{NDVI}+4.42$

Fig. 7 Regression models and their residuals-analysis plots based on combined vegetation indices $(n=80)$

selected for biomass estimation models, which based on the reflectance of NIR and red spectral wavelength. It showed that the DVI was highly significantly correlated with biomass and present more stable than other index in the laboratory measurement on different dehydration level of Pyropia. In the study on biomass estimation of Spartina alterniflora, Zhou et al. [61] also proved that the quadratic regression model of the DVI 


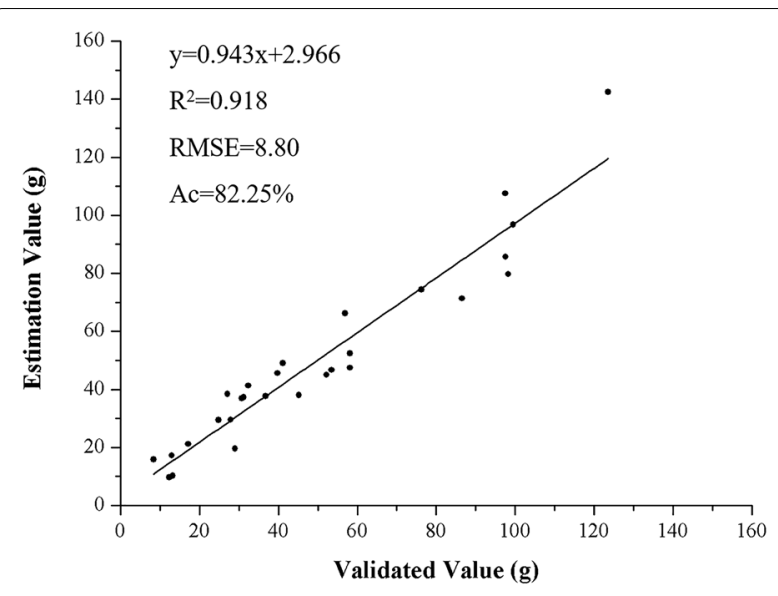

Fig. 8 Relationship between the estimated and validated value of $P$. yezoensis biomass

was more suitable than other vegetation indices. Moreover, in the present study, the regression model of Biomass $=-5.550 \mathrm{DVI}^{2}+105.410 \mathrm{DVI}+7.530$ shows high accuracy on biomass estimation of Pyropia. It is the first success in biomass estimation on cultivated macroalgae using UAV-based multi-spectral imaging, which suggests that there is high potential to establish efficient, accurate, and high-throughput phenotyping for mariculture.

On the other hand, red and brown macroalgae have more pigments besides chlorophyll-a, which could be characterized wavelength-specific absorbance and reflectance properties and used for high-throughput phenotyping [32]. Hu et al. [21] reported that the phycourobilin and phycoerythrobilin, which were also the dominant pigments of Pyropia, resulted in spectral curvatures between 469 and $555 \mathrm{~nm}$ using hyperspectral satellite. However, in this study, we did not discover the similar phenomenon, which might be limited by the broad band width of the multispectral sensor. Therefore, if the UAV platform is equipped with a hyperspectral sensor, more spectral features might be used for more accurate estimation [55]. In fact, in our laboratory experiment on dehydration effect, the continuous spectrum with high resolution presented detailed information among different dehydration levels of $P$. yezoensis. After exploring more specific indices for different phenotraits under controllable conditions in the lab, it could be expected to utilise UAV equipped with a hyperspectral sensor for high-throughput phenotyping of more traits and more cultured macroalgae species in the field. The highthroughput acquisition of more morphological and physiological phenotraits of macroalgae would contribute to the phenomics study of the interactions between the genome and the environment.
Moreover, a UAV-based spectral imaging system can be utilised in ecosystem-based management by providing prompt and instinctive information on large-scale monitoring. Several studies reported that large-scale cultivation of macroalgae benefited the coastal environment by extracting inorganic nutrients (such as nitrogen, phosphorus, and carbon dioxide), mitigating adverse environmental impacts, and reducing the occurrence of harmful algal blooms [14, 30, 41, 53]. The UAV-based spectral imaging systems could help to reasonably manage cultivated area, and predict algal blooms [25]. And after further validation on larger scale and a long term of years, the biomass estimation model established in this study will be benefit the cultivation management of $P$. yezoensis for sustainable aquaculture.

\section{Conclusions}

This study established a regression model using a vegetation index (DVI) and a feasible method to estimate the biomass of Pyropia using UAV-based multispectral imaging. High accuracy of the estimated model was validated by the strong similarities between estimated and manually measured biomass. Compared with the conventional measurement, the model could monitor the spatial and temporal status of cultivated Pyropia in a large-scale and cost-saving manner.

\section{Methods \\ Experimental sites}

This study was conducted in the north of Haizhou Bay, in the midwestern coast of the Yellow Sea. Haizhou Bay, with $25 \mathrm{~km}$ of winding coastline, experiences regular semidiurnal tide. The tidal cycle is approximately $12 \mathrm{~h}$ $18 \mathrm{~min}$ and the average tidal range is approximately $344 \mathrm{~cm}$. In this area, the aquaculture area of $P$. yezoensis was more than 200 hectares in 2017 [33]. The study area consisted of three parts, plots A, B, and C (Fig. 9). The cultivation rafts of plot $\mathrm{A}$ was semi-floating in the intertidal mudflat, and those of plots $B$ and $C$ were fixed pillars in shallow sea.

\section{Image data acquisition}

Airborne multispectral and digital images of the study areas were acquired using a RedEdge-M sensor (MicaSense, USA) and a Firefly $8 \mathrm{~s}$ camera (Hawkeye, China), respectively (Fig. 10). The RedEdge-M sensor is comprised of a solid state with five spectral bands ranging from $400 \mathrm{~nm}$ to $900 \mathrm{~nm}$. The wavelengths of each band were blue ( $475 \mathrm{~nm}$ centre, $20 \mathrm{~nm}$ bandwidth), green (560 nm centre, $20 \mathrm{~nm}$ bandwidth), red (668 nm centre, $10 \mathrm{~nm}$ bandwidth), red edge $(717 \mathrm{~nm}$ centre, $10 \mathrm{~nm}$ bandwidth), and NIR (840 nm centre, $40 \mathrm{~nm}$ bandwidth). The resolution of the sensor was $1280 \times 960$ pixels with 


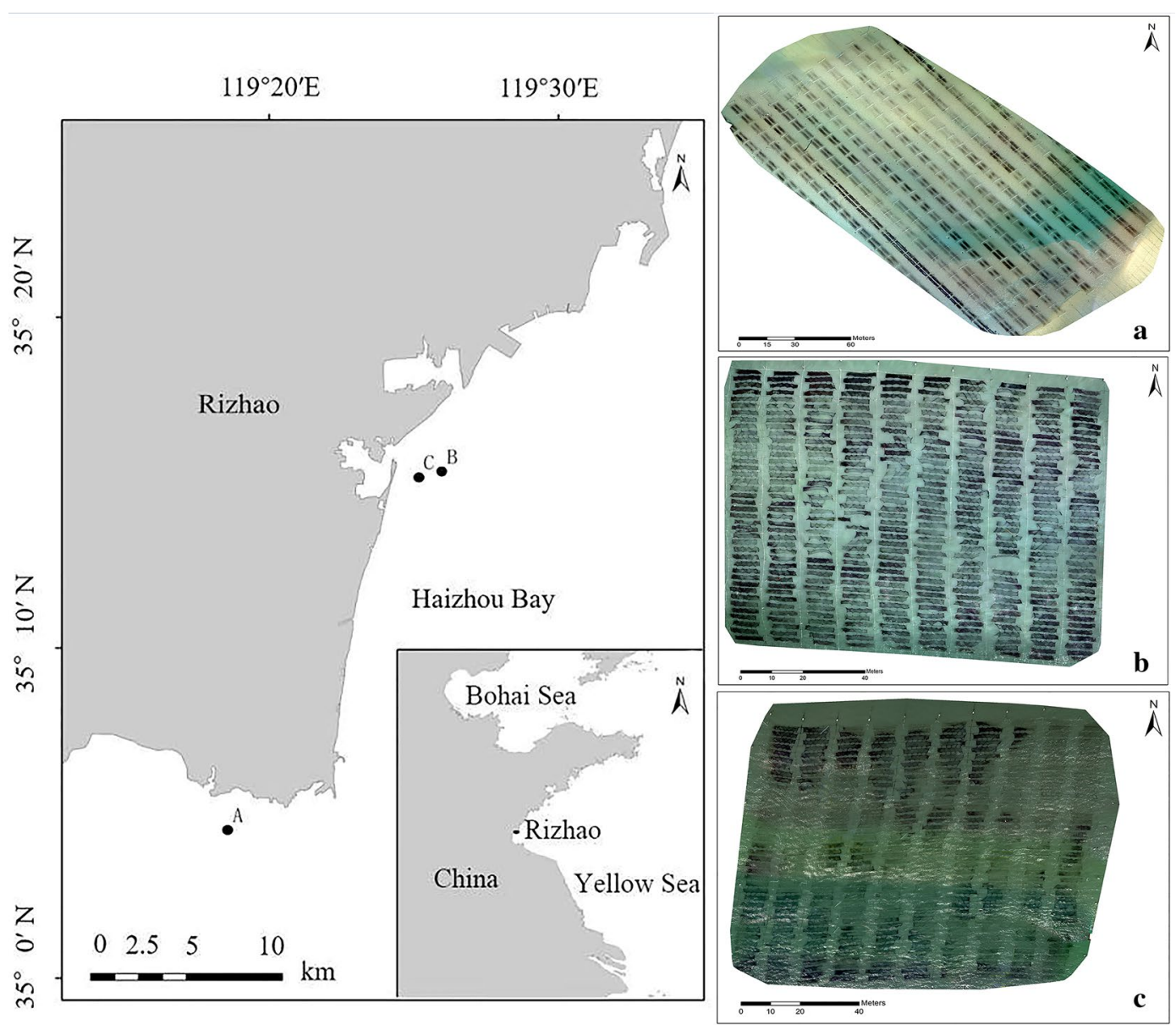

Fig. 9 Study sites with RGB images of plot A, B and C

a field of view of $47.2^{\circ}$. Both sensors were flown onboard an Ecodrone UAS-8 Multifunctional UAV (Ecotech Ecological Technology Ltd., China). The flights altitude were approximately $40 \mathrm{~m}$ above cultivated Pyropia (Table 2). The radiometric calibration images of the RedEdge- $M$ sensor were captured on a calibrated reflectance panel (MicaSense, USA) before each flight.

To investigate the multispectral reflectance characters of $P$. yezoensis when it exposed to the air or submerged in seawater, the UAV imaging was taken when ten nets were randomly selected by lifting them out of the water, in plot B on 22nd November 2018 (Table 2). Each 100 pixels $(0.6 \times 0.6 \mathrm{~m})$ were extracted from images of exposed P. yezoensis, submerged P. yezoensis and seawater for comparing their multispectral reflectance. To check the potential influence of dehydration on reflectance, a laboratory experiment was conducted on $P$. yezoensis with a series of relative water content (RWC). The $P$. yezoensis thalli were spread flat on a plate to obtain the RWC from $100 \%$ to $10 \%$ in a gradient of $10 \%$ at $10{ }^{\circ} \mathrm{C}$ room temperature following the methods of Sun et al. [47]. The spectrums of $P$. yezoensis were measured using the hyperspectral camera Specim IQ (Specim, Finland) in 400-1000 nm range. And in the field, extra experiments were carried out to decide a suitable aerial imaging time. In plot A during the low tide period, the UAV-boarded multispectral sensors were flown twice at the time of $P$. yezoensis once totally exposed to air and $1 \mathrm{~h}$ later. The 100 pixels $(0.6 \times 0.6 \mathrm{~m})$ were selected and compared their derived vegetation indices based on multispectral reflectance. Consistency in the investigated sites was ensured by determining the same global positioning system (GPS) coordinates using a Garmin 12 channel GPS receiver (Garmin, Taiwan). The field experiments were conducted twice on 6th and 7th January, 2019, respectively (Table 2).

\section{Data processing}

Data processing was conducted as shown in Fig. 11. The images were jointed and orthorectification was taken using Pix4D 4.1.2 (Lausanne, Switzerland) and Agisoft 

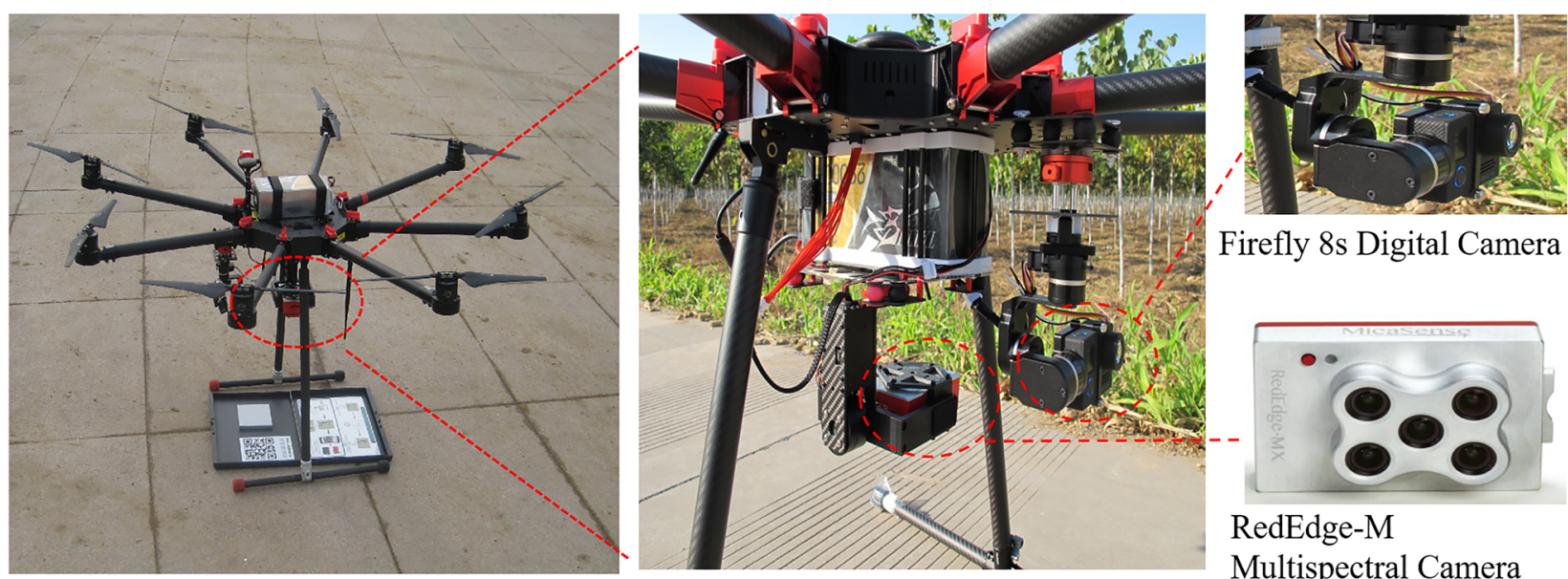

Firefly 8s Digital Camera

Fig. 10 UAV platform and sensors

Table 2 Details of the flight in this study

\begin{tabular}{|c|c|c|c|}
\hline Region & A & B & $\mathrm{C}$ \\
\hline Flight date & $\begin{array}{l}\text { 6th and 7th Jan, } \\
2019\end{array}$ & $\begin{array}{l}\text { 22nd Nov, } 2018 \\
\text { and 13th Jan, } \\
2019\end{array}$ & 13th Jan, 2019 \\
\hline Area $\left(m^{2}\right)$ & 25200 & 0 & 12800 \\
\hline Flight time (min) & & 520 & 20 \\
\hline Flight height (m) & 4( & 40 & 40 \\
\hline Line spacing (m) & 10 & 10 & 10 \\
\hline Forward overlap & $\begin{array}{l}\text { Average over- } \\
\text { lap }>70 \% \text { (Timer } \\
\text { exposure mode) }\end{array}$ & $\begin{array}{l}\text { Average over- } \\
\text { lap }>70 \% \text { (Timer } \\
\text { exposure mode) }\end{array}$ & $\begin{array}{l}\text { Average over- } \\
\text { lap }>70 \% \\
\text { (Timer } \\
\text { exposure } \\
\text { mode) }\end{array}$ \\
\hline Side overlap & $70 \%$ & $70 \%$ & $70 \%$ \\
\hline Resolution & $1280 \times 960$ & $1280 \times 960$ & $1280 \times 960$ \\
\hline
\end{tabular}

Photoscan software. They were then subjected to geometric correction processing using the measurements of the 12 ground control points. After geometric correction, the radiometric calibrations were performed using Pix4D software. Radiometric calibration was carried out using the calibration images of the reflectance panel with known reflectance values. Each time before the UAV platform took off to the object regions, the multispectral camera acquired the images of the reflectance panel in advance. Using the corresponding values of the calibrated reflectance panel, the captured images data were carried out the radiometric correction using Pix4D or Photoscan automatically. Radiometric corrections were used to improve radiometric data quality and correct the spectral reflectance from images. The images acquired by the UAV-based multispectral

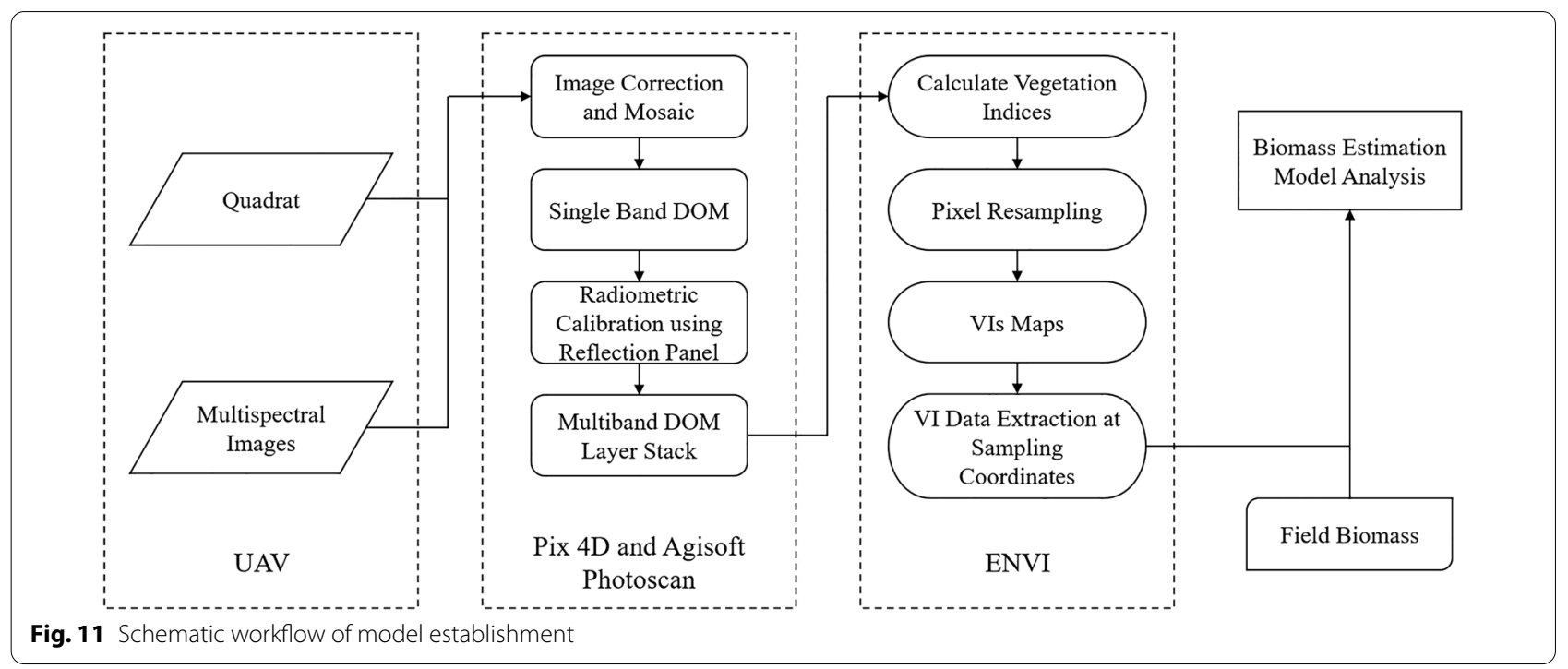


sensors were performed using ENVI 5.1 software. To filter out the noise formed by the seawater background, kernel neighbourhood maximal calculation was performed. Resampling was used to control the number of pixel points involved in computation.

The reflectance values were derived using ENVI 5.1 software. The four vegetation indices, the difference vegetation index (DVI), ratio vegetation index (RVI), normalised difference of red edge (NDRE), and normalised difference vegetation index (NDVI) were calculated following the equations shown in Table 3 in ENVI 5.1.

In the equations of Table $3, \rho_{N I R}, \rho_{R}$, and $\rho_{R E}$ are the measured reflectance of NIR, red, and red edge bands, respectively.

The reflectance of $P$. yezoensis measured by the Specim IQ hyperspectral camera was transformed to RedEdge-M equivalent reflectance using the spectral response function of the RedEdge-M sensor, as the following equation.

$$
R_{\text {RedEdge-M }}\left(\lambda_{i}\right)=\frac{\int F_{0}(\lambda) S_{i}(\lambda) R(\lambda) d \lambda}{\int F_{0}(\lambda) S_{i}(\lambda) d \lambda}
$$

In the equation above, the $S_{i}(\lambda)$ is the spectral response function of the $i$-th band of the RedEdge-M, $F_{0}(\lambda)$ is the average solar irradiance, $R(\lambda)$ is the measured reflectance

\section{Table 3 Vegetation indices used in this study}

\begin{tabular}{lll}
\hline Vegetation Index & Formula & Reference \\
\hline RVI & $\rho_{N I R} / \rho_{R}$ & {$[27]$} \\
DVI & $\rho_{N / R} \rho_{R}$ & {$[50]$} \\
NDRE & $\left(\rho_{N / R}-\rho_{R E}\right) /\left(\rho_{N I R}+\rho_{R E}\right)$ & {$[15]$} \\
NDVI & $\left(\rho_{N / R}-\rho_{R}\right) /\left(\rho_{N I R}+\rho_{R}\right)$ & {$[22]$} \\
\hline
\end{tabular}

by the hyperspectral camera, and $R_{\text {RedEdge-M }}(\lambda)$ is the RedEdge-equivalent reflectance. The processes were performed using ENVI 5.1.

\section{Field measurement of biomass}

Matching the acquisition time of UAV multispectral imaging data, the field samples were synchronously obtained in plots B and C on 13 January 2019 (Table 2). Thirty-six $P$. yezoensis nets were randomly selected in plots B and C (Fig. 12). Each net was sampled by three $0.6 \times 0.6 \mathrm{~m}$ quadrats within $1 \mathrm{~h}$ after $P$. yezoensis was completely exposed to the air. The locations of all sample quadrats were determined using the Garmin 12 channel GPS receiver. The $P$. yezoensis biomass of each quadrat was acquired by weighing the constant weight after drying in a heat oven (BPG-9070A) at $80^{\circ} \mathrm{C}$ [5].

\section{Estimation model establishment and assessment}

The regression of vegetation indices provides a simple and effective method for estimating biomass. In this study, the four vegetation indices were calculated from multispectral images using the mean reflectance values of a $0.6 \times 0.6 \mathrm{~m}$ pixel in accordance with the same field sampling site (as determined using GPS coordinates). Eighty field quadrats out of a total of 108 were selected randomly as the training data for the establishment of the linear or non-linear regression model, and the remaining 28 quadrats were used for model validation. The simple linear or square regressions were used to estimate the parameters of calculation equations based on single or combined vegetation indices. The accuracy of each model was assessed using the root mean square error (RMSE), relative estimated accuracy (Ac) and coefficient
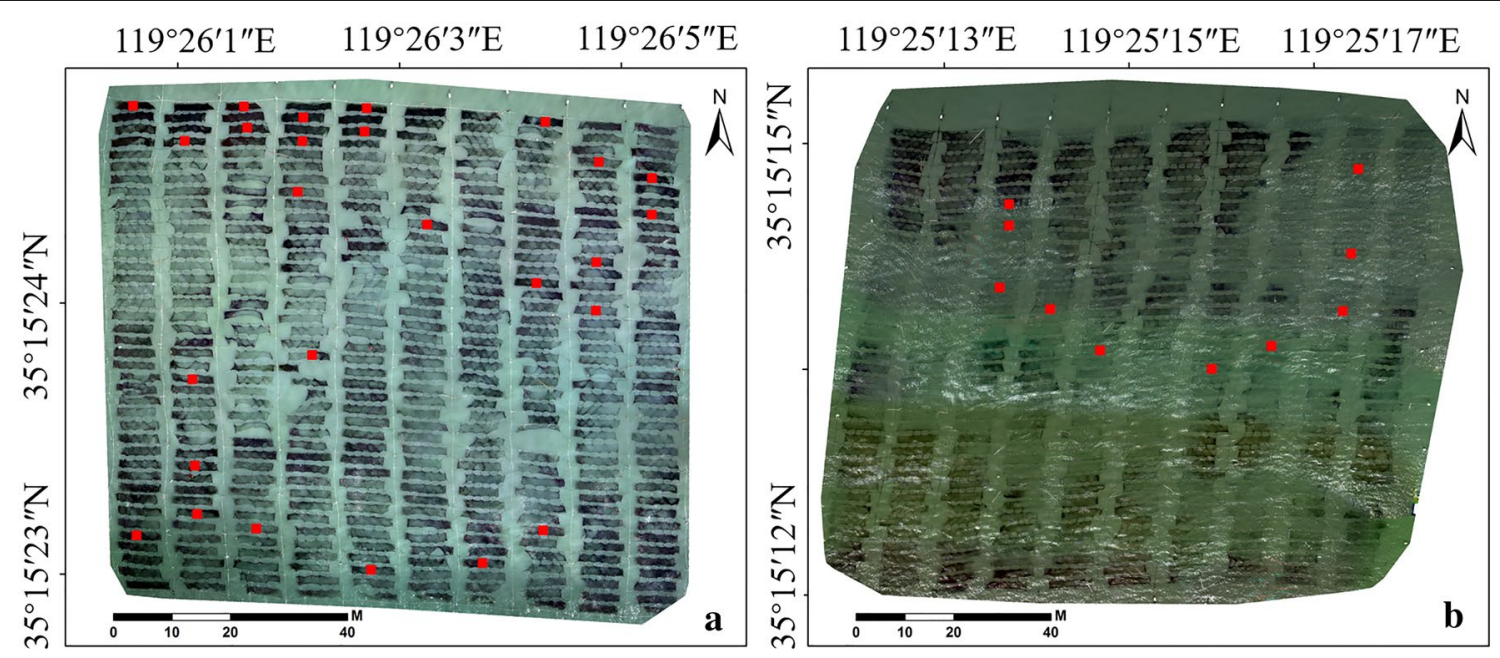

Fig. 12 Sampling points in the study plot $B(\mathbf{a})$ and $C(\mathbf{b})$ 
of determination $\left(R^{2}\right)$. The smaller the RMSE value, the better the accuracy. Furthermore, the higher Ac and $R^{2}$ values indicate greater similarities between the estimated and true values. The equations for these parameters are as follows:

$$
\begin{aligned}
& \mathrm{R}^{2}=1-\sum_{i=1}^{n}\left(X_{i}-Y_{i}\right)^{2} / \sum_{i=1}^{n}\left(X_{i}-\bar{X}\right)^{2} \\
& \mathrm{RMSE}=\sqrt{\sum_{i=1}^{n}\left(X_{i}-Y_{i}\right)^{2} / n}
\end{aligned}
$$

$$
\mathrm{Ac}=(1-\operatorname{RMSE} / \bar{X}) \times 100 \%
$$

In the equations above, $X$ and $Y$ are the measured and estimated biomass values of sample $i, n$ is the number of samples, and $\bar{X}$ is the average value of total measured biomass. The regression diagnostic plots of the different vegetation indices and the distribution of the predicted values and residuals were used for model assessment.

\begin{abstract}
Abbreviations
UAV: Unmanned aerial vehicle; RWC: Relative water content; VI: Vegetation index; NIR: Near infrared; NDVI: Normalised difference vegetation index; RVI: Ratio vegetation index; DVI: Difference vegetation index; NDRE: Normalised difference of red edge; $R^{2}$ : Coefficient of determination; RMSE: Root mean square error; Ac: Relative estimated accuracy; ENVI: Environment for Visualising Images; GPS: Global Position System; DOM: Digital orthoimage.
\end{abstract}

\section{Acknowledgements}

We thank the Jinshuiyuan Food Co., Ltd. (Rizhao, China) for offering Pyropia cultivated plots and assisting in all field measurements. We also thank Xuefeng Zhong and Zhiyang Wang for their helps in the field investigation.

\section{Authors' contributions}

SC conducted the field work, data analysis and drafted the manuscript. YM proposed the conceptualization of the study and reviewed the manuscript. GD designed the study, coordinated experiment implementation and revised the manuscript. NW and KH operated the UAV and processed the data. ZM helped improve the experimental design and the English language. BS, YCh, YCa and JW collected the field data. All authors read and approved the final manuscript.

\section{Funding}

Fundamental Research Funds for the Central Universities (202065006). The Marine S\&T Fund of Shandong Province for Pilot National Laboratory for Marine Science and Technology (Qingdao) (No. 2018SDKJ0302-4). National Key R\&D Program of China (2018YFC1406704). National Key R\&D Program of China (2018YFD0900106). National Natural Science Foundation of China (32060829).

\section{Availability of data}

The datasets analysed during the current study are available from the corresponding author on reasonable request.

\section{Ethics approval and consent to participate}

Not applicable.

\section{Consent for publication}

All authors have read and consented to publication of this article.

\section{Competing interests}

The authors declare that they have no competing interests.

\section{Author details}

${ }^{1}$ Key Laboratory of Marine Genetics and Breeding (Ministry of Education), College of Marine Life Sciences, Ocean University of China, Qingdao 266003, People's Republic of China. ${ }^{2}$ Key Laboratory of Utilization and Conservation of Tropical Marine Bioresource (Ministry of Education), College of Fisheries and Life Science, Hainan Tropical Ocean University, Sanya 572022, People's Republic of China. ${ }^{3}$ Laboratory for Marine Biology and Biotechnology, Pilot National Laboratory for Marine Science and Technology (Qingdao), Qingdao 266000, People's Republic of China. ${ }^{4}$ Xi' an Ecotech Spectral Imaging and Eco-drone Remote Sensing Research Center Co., Ltd., Xi' an 710000, People's Republic of China.

Received: 28 February 2020 Accepted: 18 January 2021

Published online: 04 February 2021

\section{References}

1. Araus JL, Cairns JE. Field high-throughput phenotyping: the new crop breeding frontier. Trends Plant Sci. 2014;19(1):52-61.

2. Bendig J, Bolten A, Bennertz S, Broscheit J, Eichfuss S, Bareth G. Estimating biomass of barley using crop surface models (CSMs) derived from UAVbased RGB imaging. Remote Sens. 2014;6:10395-412.

3. Bito T, Teng F, Watanabe F. Bioactive compounds of edible purple laver Porphyra sp. (Nori). J Agric Food Chem. 2017;65:10685-92.

4. Blouin NA, Brodie JA, Grossman AC, Xu P, Brawley SH. Porphyra: a marine crop shaped by stress. Trends Plant Sci. 2011;16:29-37.

5. Cabrera-Bosquet L, Molero G, Stellacci A, Bort J, Nogues S, Araus J. NDVI as a potential tool for predicting biomass, plant nitrogen content and growth in wheat genotypes subjected to different water and nitrogen conditions. Cereal Res Commun. 2011;39:147-59.

6. Casal G, Kutser T, Domínguez-Gómez JA, Sánchez-Carnero N, Freire J. Mapping benthic macroalgal communities in the coastal zone using CHRIS-PROBA mode 2 images. Estuar Coast Shelf. 2011;94:281-90.

7. Casal G, Sánchez-Carnero N, Sánchez-Rodríguez E, Freire J. Remote sensing with SPOT-4 for mapping kelp forests in turbid waters on the south European Atlantic shelf. Estuar Coast Shelf S. 2011;91:371-8.

8. Casal G, Kutser T, Domínguez-Gómez JA, Sánchez-Carnero N, Freire J. Assessment of the hyperspectral sensor CASI-2 for macroalgal discrimination on the Ría de Vigo coast (NW Spain) using field spectroscopy and modelled spectral libraries. Cont Shelf Res. 2013;55:129-40.

9. Cen H, Wan L, Zhu J, Li Y, Li X, Zhu Y, et al. Dynamic monitoring of biomass of rice under different nitrogen treatments using a lightweight UAV with dual image-frame snapshot cameras. Plant Methods. 2019;15:32.

10. Dierssen HM, Chlus A, Russell B. Hyperspectral discrimination of floating mats of seagrass wrack and the macroalgae Sargassum in coastal waters of Greater Florida Bay using airborne remote sensing. Remote Sens Environ. 2015;167:247-58.

11. Doughty CL, Cavanaugh KC. Mapping coastal wetland biomass from high resolution Umanned Aerial Vehicle (UAV) imagery. Remote Sens. 2019;11(5):540.

12. FAO (Food and Agriculture Organization of the United Na-tions). Fisheries and Aquaculture Information and Statistics Branch. 2019. http://www.fao. org/fishery/en. Ac-cessed July 102019.

13. Gao G, Clare AS, Rose C, Caldwell GSG. Ulva rigida in the future ocean: potential for carbon capture, bioremediation and biomethane production. Bioenergy. 2018;10:39-51.

14. Gao G, Gao Q, Bao M, Xu J, Li X. Nitrogen availability modulates the effects of ocean acidification on biomass yield and food quality of a marine crop Pyropia yezoensis. Food Chem. 2019;271:623-9.

15. Gitelson A, Merzlyak MN. Quantitative estimation of chlorophyll-a using reflectance spectra: experiments with autumn chestnut and maple leaves. J Photochem Photobiol B-Biol. 1994;22(3):247-52.

16. Gong Y, Duan B, Fang S, Zhu R, Wu X, Ma Y, et al. Remote estimation of rapeseed yield with unmanned aerial vehicle (UAV) imaging and spectral mixture analysis. Plant Methods. 2018;14:70. 
17. Großkinsky DK, Svensgaard J, Christensen S, Roitsch T. Plant phenomics and the need for physiological phenotyping across scales to narrow the genotype-to-phenotype knowledge gap. J Exp Bot. 2015;66:5429-40.

18. Gutierrez M, Reynolds MP, Klatt AR. Association of water spectral indices with plant and soil water relations in contrasting wheat genotypes. J Exp Bot. 2010;61:3291-303.

19. Han L, Yang $G$, Dai $H$, Xu B, Yang $H$, Feng $H$, et al. Modeling maize aboveground biomass based on machine learning approaches using UAV remote-sensing data. Plant Methods. 2019;15:10.

20. Hu C. A novel ocean color index to detect floating algae in the global oceans. Remote Sens Environ. 2009;113:2118-29.

21. Hu C, Cannizzaro J, Carder KL, Muller-Karger FE, Hardy R. Remote detection of Trichodesmium blooms in optically complex coastal waters: examples with MODIS full-spectral data. Remote Sens Environ 2010;114:2048-58.

22. Huete AR, Liu HQ, Batchily K, Leeuwen W. A comparison of vegetation indices over a global set of TM images for EOS-MODIS. Remote Sens Environ. 1997;59(3):440-51.

23. Jamieson PD, Porter JR, Wilson DR. A test of the computer simulation model ARCWHEAT1 on wheat crops grown in New Zealand. Field Crop Res. 1991;27:337-50.

24. Jiang H, Zou D, Lou W, Chen W, Yang Y. Growth and photosynthesis by Gracilariopsis lemaneiformis (Gracilariales, Rhodophyta) in response to different stocking densities along Nan'ao Island coastal waters. Aquaculture. 2019;501:279-84.

25. Jiang X, Gao Z, Zhang Q, Wang Y, Tian X, Shang W, et al. Remote sensing methods for biomass estimation of green algae attached to nursery-nets and raft rope. Mar Pollut Bull. 2020;150:110678.

26. Jin X, Madec S, Dutartre D, Solan BD, Comar A, Bare F. High-Throughput Measurements of Stem Characteristics to Estimate Ear Density and Above-Ground Biomass. Plant Phenomics. 2019:2019:4820305.

27. Jordan CF. Derivation of leaf-area index from quality of light on the forest floor. Ecology. 1969;50(4):663-6.

28. Khan Z, Rahimi-Eichi V, Haefele S, Garnett T, Miklavcic SJ. Estimation of vegetation indices for high-throughput phenotyping of wheat using aerial imaging. Plant Methods. 2018;14:20.

29. Kim JK, Kraemer GP, Yarish C. Emersion induces nitrogen release and alteration of nitrogen metabolism in the intertidal genus Porphyra. PLoS ONE. 2013;8:e69961.

30. Kim JK, Yarish C, Hwang EK, Park M, Kim Y. Seaweed aquaculture: cultivation technologies, challenges and its ecosystem services. Algae. 2017;32:1-13.

31. Lavender SJ, Pinkerton MH, Moore GF, Aiken J, Blondeau-Patissier D. Modification to the atmospheric correction of SeaWiFS ocean colour images over turbid waters. Cont Shelf Res. 2005;25:539-55.

32. Li L, Zhang Q, Huang D. A review of imaging techniques for plant phenotyping. Sensors. 2014;14:20078-111.

33. Liang Z, Sun T, Wang W, Liu F, Cao Y, Liang Q, et al. The temporal and spatial distribution characteristics of nutrient and community structure of phytoplankton and their relationship in the Pyropia culture area in Rizhao. Progress in Fishery Science. 2018. https://doi.org/10.19663/j.issn2 095-9869.20180702001

34. Liu Y, Liu S, Li J, Guo X, Wang S, Lu J. Estimating biomass of winter oilseed rape using vegetation indices and texture metrics derived from UAV multispectral images. Comput Electron Agric. 2019;166:105026.

35. Lu N, Zhou J, Han Z, Li D, Cao Q, Yao X, et al. Improved estimation of aboveground biomass in wheat from RGB imagery and point cloud data acquired with a low-cost unmanned aerial vehicle system. Plant Methods. 2019;15:17.

36. Major DJ, Baumeister R, Touré A, Zhao S. Methods of measuring and characterizing the effects of stresses on leaf and canopy signatures. Digital imaging spectral techniques: applications to precision Agriculture and Crop Physiology. 2003;66:81-93.

37. Maréchal ME, Plants Freshwater. Challenges and Expectations. Front. Plant Sci. 2019;10:1545.

38. Menzel MI, Tittmann S, Buehler J, Preis S, Wolters N, Jahnke S, et al. Noninvasive determination of plant biomass with microwave resonators. Plant cell and Environ. 2009;32:368-79.

39. Mistele B, Schmidhalter U. Spectral measurements of the total aerial N and biomass dry weight in maize using a quadrilateral-view optic. Field Crop Res. 2008;106:94-103.
40. Näsi R, Viljanen N, Kaivosoja J, Alhonoja K, Hakala T, Markelin L, et al. Estimating biomass and nitrogen amount of barley and grass using UAV and aircraft based spectral and photogrammetric 3D features. Remote Sens. 2018;10:1082

41. Neori A, Chopin T, Troell M, Buschmann AH, Kraemer GP, Halling C, et al. Integrated aquaculture: rationale, evolution and state of the art emphasizing seaweed biofiltration in modern mariculture. Aquaculture. 2004;231:361-91.

42. Sankaran $S$, Khot LR, Espinoza CZ, Jarolmasjed S, Sathuvalli VR, Vandemark GJ, et al. Low-altitude, high-resolution aerial imaging systems for row and field crop phenotyping: a review. Eur J Agron. 2015;70:112-23.

43. Seckbach J. Introduction to globally changing environment. In: Israel A, Einav R, Seckbach J, editors. Seaweeds and their role in Globally Changing Environments, vol. 15. Berlin: Springer; 2010.

44. Shan T, Li Q, Wang X, Su L, Pang S. Assessment of the genetic connectivity between farmed populations on a typical kelp farm and adjacent spontaneous populations of Saccharina japonica (Phaeophyceae, Laminariales) in China. Front Mar Sci. 2019;6:494.

45. Shi W, Wang M. Green macroalgae blooms in the Yellow Sea during the spring and summer of 2008. J Geophys Res Oceans. 2009;114:C12010.

46. Shi Y, Thomasson JA, Murray SC, Pugh NA, Rooney WL, Shafian S, et al. Unmanned aerial vehicles for high-throughput phenotyping and agronomic research. PLoS ONE. 2016;11:e0159781.

47. Sun P, Tang X, Bi G, Xu K, Kong F, Mao Y. Gene expression profiles of Pyropia yezoensis in response to dehydration and rehydration stresses. Mar Genom. 2019;43:43-9.

48. Tagle Casapia MX. Study of radiometric variations in unmanned aerial vehicle remote sensing imagery for vegetation mapping. Master's Thesis, Lund University, Lund, Sweden; 2017.

49. Tardieu F, Cabrera-Bosquet L, Pridmore T, Bennett M. Plant phenomics, from sensors to knowledge. Curr Biol. 2017;27(15):R770-83.

50. Tucker CJ. A spectral method for determining the percentage of green herbage material in clipped samples. Remote Sens Environ. 1980;9(2):175-81.

51. Xiao Y, Zhang J, Cui T, Gong J, Liu R, Chen X, et al. Remote sensing estimation of the biomass of floating Ulva prolifera and analysis of the main factors driving the interannual variability of the biomass in the Yellow Sea. Mar Pollut Bull. 2019;140:330-40.

52. Yang Y, Chai R, He Y. Early detection of rice blast (Pyricularia) at seedling stage in Nipponbare rice variety using near-infrared hyper-spectral image. Afr J Biotechnol. 2012;11:6809-17.

53. Yang Y, Chai Z, Wang Q, Chen W, He Z, Jiang S. Cultivation of seaweed Gracilaria in Chinese coastal waters and its contribution to environmental improvements. Algal Res. 2015;9:236-44.

54. Yu N, Li L, Schmitz N, Tian LF, Greenberg JA, Diers BW. Development of methods to improve soybean yield estimation and predict plant maturity with an unmanned aerial vehicle based platform. Remote Sens Environ. 2016;187:91-101

55. Yue J, Yang G, Li C, Li Z, Wang Y, Feng H, Xu B. Estimation of winter wheat above-ground biomass using unmanned aerial vehicle-based snapshot hyperspectral sensor and crop height improved models. Remote Sens. 2017;9(7):708.

56. Zaman-Allah M, Vergara O, Araus JL, Tarekegne A, Magorokosho C, ZarcoTejada PJ, et al. Unmanned aerial platform-based multi-spectral imaging for field phenotyping of maize. Plant Methods. 2015;11:35.

57. Zhang C, Kovacs JM. The application of small unmanned aerial systems for precision agriculture: a review. Precis Agric. 2012;13:693-712.

58. Zhang L, Zhang H, Niu Y, Han W. Mapping maize water stress based on UAV multispectral remote sensing. Remote Sens. 2019;11(6):605.

59. Zhao $X$, Zhang $X, X u$ P. Research on the photosynthetic efficiency of strains of Pyropia yezoensis under different conditions. Mar Sci Bull. 2010;29:623-8.

60. Zhou J, Yungbluth D, Vong CN, Scaboo A, Zhou J. Estimation of the Maturity Date of Soybean Breeding Lines Using UAV-Based Multispectral Imagery. Remote Sens. 2019;11:2075.

61. Zhou ZM, Yang YM, Chen BQ. Estimating Spartina alterniflora fractional vegetation cover and above ground biomass in a coastal wetland using SPOT6 satellite and UAV data. Aquat Bot. 2018;144:38-45.

\section{Publisher's Note}

Springer Nature remains neutral with regard to jurisdictional claims in published maps and institutional affiliations. 